\title{
Sustainable use and commercialization of bushmeat in Colombia Toward the operationalization of legal frameworks
}

\author{
Nathalie van Vliet, Juanita Gomez, Sebastián Restrepo, Germán Andrade, Claude García, John Emmanuel Fa, \\ Graham Webb, Rosie Cooney, Brian Child and Robert Nasi
}

\section{Key points}

- Under Colombian law, the sale of game to cover basic needs (e.g. housing, health, education) or to buy other food items is not allowed, since this is considered commercial hunting and does not fall under provisions allowing for subsistence bushmeat hunting.

- Law 611 (2000) opened the path to legal commercial use of wildlife. In practice, however, the requirements for obtaining legal permits for commercial hunting activities make it extremely challenging for rural communities to obtain them.

- Aware of the role that bushmeat plays in food security, family economy and cultural identity among many rural communities, a number of high-profile Colombian environmental institutions participated in a workshop in 2015 to discuss the operationalization of the legal framework for the trade in bushmeat by rural communities.

- One of the main conclusions of the workshop was that commercial hunting regulations need to legally distinguish between large-scale commercial hunting and the sale of surplus game by subsistence hunters in rural communities. Indeed, these two types of commercial hunting differ in terms of the scale of action, the governance systems in place and the ways in which benefits are equitably distributed among different actors.

- The main recommendation was that the regulatory framework should adopt flexible management processes for the local development of sustainable management rules (e.g. list of tradable species, quotas, open seasons, monitoring and evaluation systems). This would allow for the recognition of the specificities of each socio-ecological context, rather than imposing a national-level framework that would likely fail, given Colombia's diverse biological and cultural characteristics.

\section{The problem}

Despite the cultural transformations brought about by globalization, use and trade of wild meat (or bushmeat) still plays an important role in many rural economies, contributing to local livelihoods and to household food security (Nasi et al. 2008). However, existing legal frameworks in many user countries lack clear definitions of sustainable use rights by rural communities, and often fail to provide well-defined pathways for enabling the use of bushmeat at sustainable levels to meet legitimate needs.

In Colombia, more flexible regulatory bases for the sustainable use of natural resources were included in articles 329 and 330 of the 1991 Constitution. These articles recognize the sovereignty of indigenous communities and their right to regulate the use of their natural capital. Under Colombian law, subsistence hunting is allowed "provided that it is not totally, partially, temporarily or definitely prohibited by the administrative entity in charge of natural resources" (Law 84 [1989]). Subsistence hunting may be carried out throughout the national territory, as long as is not prohibited by any of the state authorities.

However, under the current definition of subsistence hunting, the trade of game to cover other basic needs (e.g. house rents, health, education) or to buy food, is considered commercial hunting, and is therefore forbidden. Rural hunters are in principle able to sell bushmeat if they obtain a legal permit issued by the regional environmental authority, under complex requirements contained in Decree 4688 (2005), Decree 2041 (2014), and Resolution 1292 (2006). However, these regulations provide no operational frameworks that adequately respond to the specific realities of rural communities within the ecosystems concerned. Current bottlenecks in the legal framework and in the administrative process in Colombia encourage clandestine bushmeat markets and inspire a variety of strategies to avoid police controls (van Vliet et al. 2014). Despite the illegality of the trade, studies undertaken in different regions of the country clearly indicate the existence of trade networks and the importance of wild meat in the nutrition, culture and economy of urban and rural people.

In indigenous, peasant and afro-descendent rural communities, hunting is primarily for subsistence, although bushmeat is traded after satisfying the family's basic food needs (Quiceno et al. 2015). Rural communities sell game to purchase foods not produced locally, basic products such as soap, sugar, salt, and oil, as well as materials for hunting. In the Colombian Amazon, hunters sell about one third of their offtake (Ortega 2014; Quiceno et al. 2014). The sale of bushmeat operates within short networks, where meat is moved rapidly from rural and peri-urban areas to nearby population centers (Quiceno et al. 2015). 
Evidence suggests that rural communities throughout Colombia locally trade bushmeat, and that this is a resource of nutritional and cultural importance. It is essential that ways of improving the legal framework are explored, to help these communities overcome the operational barriers to a sustainable legal trade (van Vliet et al. 2015). This would empower local communities, secure their livelihoods and allow them to avoid illicit and unregulated practices. It would also allow better monitoring and thus foster sustainable management.

\section{What are the main legal bottlenecks for sustainable commercial use of bushmeat in Colombia?}

Subsistence hunting in Colombia is legal as long as it is to provide food for the hunter and/or his family (Law 84 [1989], article 30). Under this definition, any sale of bushmeat, even the surplus, is excluded. Thus, even though financial revenues from local wild meat trade can contribute to enhancing families' housing, health or education situation, in the eyes of the law, any type of bushmeat trade is considered "commercial hunting". Such hunting is regulated by Decree 4688 (2005), and is legally defined as hunting carried out either by a natural person or a legal entity with the express purpose of profit (article 2). Since 2000, there has been no blanket ban on commercial hunting in Colombia; however, within the current legal framework, a number of bottlenecks prevent rural communities from legally hunting for trade.

- While regional authorities may issue trade licenses for species listed as legally permitted to harvest and trade by the Ministry of Environment and Sustainable Development (MESD) (Decree 4688 [2005], article 14), this list of species and the respective trade quotas have not yet been defined. Commercial hunting activities cannot be legally carried out in Colombia until the list of species and their respective quotas are established.

- Even if regional authorities were able to issue commercial hunting licenses, the requirements to obtain them would be extremely complex for rural communities. To obtain a license, the interested party must present an environmental impact study (EIS) that includes an environmental management plan. The terms of reference for commercial hunting EIS require rigorous technical studies, which imply a significant investment that communities cannot always provide. Those studies that force the applicant to detail the commercial and financial feasibility, the costs of the infrastructure, etc. might be relevant for large-scale trade ventures, but they are ill-adapted to the situation of local communities transforming a surplus hunt into livelihood assets. Even for large-scale ventures, the relevance of studies requested on geological, geomorphological and atmospheric details seems questionable.

- Regional authorities determine annual quotas for the authorized species (Decree 4866 [2005]), based on monitoring results presented by the interested party within the three months previous to the request date. However, neither the regional authorities nor the MESD have developed formal methodologies and criteria to monitor species dynamics and to estimate harvested populations. As a result, the absence of guidelines leaves regional authorities to make subjective approvals of documents submitted or to reject requests to avoid legal complications (van Vliet et al. 2015).

\section{How is Colombia tackling the problem of legal bottlenecks for the bushmeat trade by rural communities?}

Colombian environmental institutions, aware of the crucial role that bushmeat plays in food security, family economy and cultural identity for many rural communities, met at a workshop in October 2015 to discuss the operationalization of the legal framework affecting the bushmeat trade. The MESD, the Alexander von Humboldt Biological Resources Research Institute and the Sinchi Institute - with technical support from the Center for International Forestry Research - invited experts to participate in the workshop entitled "Sustainable use and trade of bushmeat in Colombia: Operationalization of the legal framework". A total of 51 experts from Colombia and other countries met in Leticia and Puerto Nariño to share their expertise and experience, and made recommendations to strengthen and operationalize the legal framework to enable the sustainable commercial use of bushmeat by rural communities. These recommendations were based on a common understanding of bottlenecks and the analysis of lessons learned from current and past initiatives in Colombia and other parts of the world.

\section{Why is action needed?}

Experts present at the Leticia workshop considered that actions are needed to operationalize and adapt the legal framework to the realities of local communities because of the following:

- The legal notion of "commercial hunting" does not take into account that bushmeat hunting in rural communities is primarily a subsistence activity where only the surplus is occasionally sold to meet basic livelihood needs. The rural poor, especially indigenous people, value their traditional livelihoods highly and simply want the ability to adapt their efforts to maintain and improve their livelihoods to today's world.

- Local communities are affected by frequent confiscations of bushmeat, thus pushing hunters to operate in clandestine and illegal markets, marginalizing these populations even more and making future collaborations between communities and conservation agencies difficult.

- Research shows that local contexts influence the way bushmeat trade operates and its sustainability. Colombian legislation should make provisions for specific local conditions and situations.

- Rural communities who are dependent on bushmeat trade for their livelihoods, would like to operate legally to meet their basic needs.

\section{Why not just expand the definition of subsistence use?}

The idea of expanding the concept of "subsistence hunting" to include the possibility of the legal sale of surplus bushmeat, while valid, was not considered in the workshop for the following reasons:

- It is difficult to establish a quantitative limit to the notion of "surplus" in order to determine whether the trade is conducted for subsistence or profit purposes. If subsistence hunting includes the possibility of selling the surplus, without any management plan in place to ensure sustainability, then there is no guarantee that this type of subsistence trade will remain within sustainable levels and no means to control it. 
- The Colombian legal framework already offers the possibility to consider the sale of surplus in the category of commercial trade. However, there is a clear need to acknowledge the specificities of surplus trade by rural communities (as opposed to purely commercial wild life trade by private companies) and adapt the legal framework so as to acknowledge that this type of trade would need a different set of requirements adapted to the realities of local communities.

However, participants in the Leticia workshop concluded that there is a need to differentiate within the legal frameworks between the trade of surplus by subsistence hunters in rural communities, on one hand, and large-scale commercial hunting for business purposes, on the other. This is fundamental to take into account the vast differences in scale, business purposes, governance systems, modalities of distribution of the benefits and sustainability.

\section{What did the experts recommend?}

The experts gathered at the workshop agreed that the trade in bushmeat represents a real opportunity for local communities to secure direct benefits from wildlife, both nutritional as well as financial and cultural.

The Leticia workshop experts made the following recommendations:

- The regulatory frameworks for bushmeat hunting and trade must foster participatory adaptive management processes, involving scientific, traditional and local knowledge.

- Local monitoring systems for the use and trade of bushmeat should be put in place to feed adaptive management decisions. The information generated locally should be aggregated at the national level to inform the MESD through the regional autonomous corporations. In so doing, such a system should generate capacity at each level for the process to be technically viable in the long term.

- The promotion of legal and sustainable initiatives for the trade in bushmeat by rural communities requires a specific national program, that foster a better institutional coordination and guarantees the financial viability of the initiatives.

\section{Specific recommendations}

On the list of tradable species and quotas

- The definition of tradable species and quotas should be a local, adaptive and participative process that involves different actors and knowledge systems.

- Local realities (in terms of ecological, social and economic characteristics) need to be taken into account to explore maximum and minimum quotas on different species based on an adaptive management system.

- The tradable species lists and quotas can be based on the following criteria: parameters of use (offtake levels, demand etc.), biological parameters (population trends, biomass, geographic distribution), conservation status (taking into account population dynamics at a local level), and humanwildlife conflicts (e.g. crop predators).

On the terms of reference (TORs) of the environmental impact assessment for commercial hunting

- TORs should be developed through a participative process that is effective at a local scale.
- The TORs should include a short description of following components:

- environmental component (definition of management units, identification and characterization of the traded species, estimated population trends, identification of actual threats and pressures for the species, definition of a participatory monitoring plan for the species, description of the sustainable use rules and guidelines at the appropriate scale)

- economic component (access and benefits sharing plan, assessment of market chains, economic studies related to harvesting, commercial harvesting planning)

- social component (identification and recognition of local knowledge, practices and institutions related to hunting, evaluation of governance systems that could be integrated with planning strategies, assessment of impacts of hunting in cultural matters).

On the methodologies to estimate wildlife populations and ecological impacts

- Keeping in mind that population estimation involves technical complexity - sometimes unattainable for rural communities the use of indirect methods in an adaptive process is proposed, where the effort, the number of captures and the yields are documented in time.

- Considering that fauna population census methods strictly depend on the type of species defined, methods based on the density or intensity indexes of the population, such as observations per unit of effort or captures per unit of effort, are proposed.

- At the same time, governmental institutions should carry out more detailed studies on the impacts of hunting on game species, in collaboration with research institutions.

On the development of monitoring systems for bushmeat use and trade

- Monitoring systems should consider different dimensions related to hunting. At least, they must consider information on users, species and habitat, framed in a socioecological context that includes ecological, socioecological and sociocultural criteria.

- Indicators contained in monitoring systems should be adaptive and consistent with national biodiversity information systems.

- Ecological criteria

- habitat: indicators should be associated with the relationship of species to their environment, such as habitat availability

- populations: focused on the study of variables like density, distribution, behavior, breeding and taxonomic identity

- Socioecological criteria

- institutional: related to the understanding of institutional issues (formal and informal rules) that are linked to the governance of bushmeat

- Well-being: variables oriented to measuring the contributions of bushmeat to human well-being

- Sociocultural criteria

- cultural: focused on the understanding of cultural and local values and categories used to manage wildlife species

- economic: indicators should consider economic conditions of users, as well as the contribution of bushmeat to subsistence and as a source of income. 


\section{Conclusion}

Colombia has taken an unprecedented step in providing technical recommendations to adapt the national legal framework on bushmeat trade to the realities of rural communities in different eco-regions of the country. In particular, there is a tacit acknowledgement of the need for a flexible regulatory framework that allows an adaptive management and participatory process approach, at multiple scales. This will allow the development of management rules that are relevant and realistic in local contexts in order to enable both better livelihoods - without pushing people into criminality - and improved sustainability. If translated into concrete policy changes, these recommendations will open up a variety of innovative pathways for the sustainable use of wildlife. Colombia will be positioned to provide leadership on a problem that exists in many tropical forest countries around the world.

\section{Acknowledgments}

The authors are greatful for the financial support from Usaid and Ukaid through the Bushmeat Research Initiative from CIFOR. We also thank the technical support from The Instituto Alexander von Humboldt in Colombia.

\section{References}

Nasi R, Brown D, Wilkie D, Bennett E, Tutin C, van Tol G and Christophersen T. 2008. Conservation and use of wildlife-based resources: The bushmeat crisis. CBD Technical Series No.33. Montreal, Canada and Bogor, Indonesia: Secretariat of the Convention on Biological Diversity and Center for International Forestry Research (CIFOR).
Ortega MCR. 2014. Ecological sustainability of mammal hunting in Inírida region, Colombian Amazon [Master's Thesis]. Bogotá: Universidad Nacional de Colombia.

Quiceno MP, Cruz-Antia D, Moreno J and van Vliet N. 2014. Descripción de la cacería y consumo de carne de monte en el río Loretoyacu y el lago Tarapoto, Puerto nariño - Amazonas, Colombia. In Trujillo F and Duque S, eds. Los humedales de tarapoto aportes al conocimiento sobre su biodiversidad y uso. Bogotá, Colombia: Fundación Omacha.

Quiceno-Mesa MP, van Vliet N, Moreno J and Cruz-Antia D. 2015. Diagnóstico sobre el comercio de carne de monte en las ciudades de Colombia. Occasional Paper 136. Bogor, Indonesia: Center for International Forestry Research (CIFOR). http://www.cifor.org/ library/5740/diagnostico-sobre-el-comercio-de-carne-de-monteen-las-ciudades-de-colombia/.

van Vliet N, Quiceno-Mesa MP, Cruz-Antia D, Morsello C, Adams C, Mori F, Yagüe B, Hernández S, Bonilla T, Tellez L et al. 2014. Bushmeat in the tri-frontier region of Brazil, Peru and Colombia:Demise or persistence? Occasional Paper 118. Bogor, Indonesia: Center for International Forestry Research (CIFOR). http://www.cifor.org/library/5363/ bushmeat-in-the-tri-frontier-region-of-brazil-peru-and-colombiademise-or-persistence.

van Vliet N, Gomez J, Quiceno-Mesa MP, Escobar JF, Andrade G, Vanegas $L$ and Nasi R. 2015. Sustainable wild life management and legal commercial use of bushmeat in Colombia: The resource remains at the cross road. International Forestry Review 17(4):438-47.

\begin{tabular}{|c|c|c|}
\hline CGIAR & $\begin{array}{l}\text { RESEARCH } \\
\text { PROGRAM ON } \\
\text { Forests, Trees and } \\
\text { Agroforestry }\end{array}$ & $\begin{array}{l}\text { This research was carried out by CIFOR as part of the CGIAR Research Program on Forests, Trees and } \\
\text { Agroforestry (CRP-FTA). This collaborative program aims to enhance the management and use of } \\
\text { forests, agroforestry and tree genetic resources across the landscape from forests to farms. CIFOR } \\
\text { leads CRP-FTA in partnership with Bioversity International, CATIE, CIRAD, the International Center for } \\
\text { Tropical Agriculture and the World Agroforestry Centre. }\end{array}$ \\
\hline
\end{tabular}
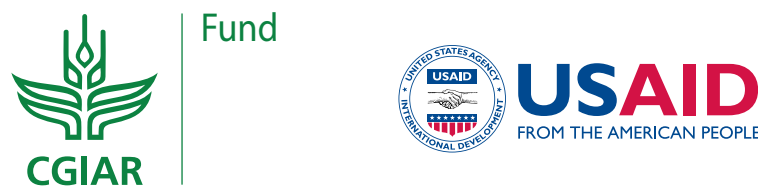

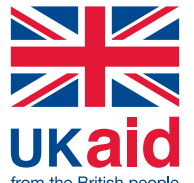


